\title{
Use of Chinese medicine by cancer patients: a review of surveys
}

\author{
Bridget Carmady and Caroline A Smith ${ }^{*}$
}

\begin{abstract}
Chinese medicine has been used to treat a variety of cancer-related conditions. This study aims to examine the prevalence and patterns of Chinese medicine usage by cancer patients. We reviewed articles written in English and found only the Chinese medicine usage from the studies on complementary and alternative medicine (CAM). Seventy four (74) out of 81 articles reported rates of CAM usage ranging from 2.6 to 100\%. Acupuncture was reported in 71 out of 81 studies. Other less commonly reported modalities included Qigong ( $n=17)$, Chinese herbal medicine $(n=11)$, Taichi $(n=10)$, acupressure $(n=6)$, moxibustion $(n=2)$, Chinese dietary therapy $(n=1)$, Chinese massage $(n=1)$, cupping $(n=1)$ and other Chinese medicine modalities $(n=19)$. This review also found important limitations of the English language articles on CAM usage in cancer patients. Our results show that Chinese medicine, in particular Chinese herbal medicine, is commonly used by cancer patients. Further research is warranted to include studies not written in English.
\end{abstract}

\section{Background}

Conventional cancer treatments such as chemotherapy and radiation therapy have shown some effectiveness for reducing or eradicating cancers; however, they can produce unpleasant side effects, e.g. nausea, vomiting, changes in bowel habits, fatigue and hair loss. Chinese medicine is increasingly used as an adjunctive treatment option for cancer patients and a way of reducing or managing side effects of conventional cancer treatment.

Chinese medicinal herbs such as Ginkgo biloba has been reported to have chemo-preventive activities for treating certain cancers such as ovarian, breast and brain [1]. Acupuncture is being used to relieve side effects of conventional cancer treatment. While some laboratory and clinical research found some immune boosting capabilities of acupuncture in cancer patients $[2,3]$, most clinical research has focused on symptom management, in particular, the management of chemotherapy induced nausea and vomiting [4-6].

This study reviews the articles published in English language complementary and alternative medicine (CAM) literature on the prevalence and patterns of Chinese medicine usage by cancer patients and informs patients,

\footnotetext{
* Correspondence: caroline.smith@uws.edu.au

Centre for Complementary Medicine Research, University of Western Sydney, Locked Bag 1797, Penrith South DC 2751, New South Wales, Australia
}

researchers, health care providers and policy makers of the current use of Chinese medicine in the CAM context.

\section{Methods \\ Literature search}

Our working definition of CAM was an inclusive term incorporating both complementary medicine and therapies (modalities and/or systems), namely the concepts of health and medical systems, practices and products not currently recognised as part of conventional medicine, alternative medicine, traditional medicine (indigenous medicine and practices), and integrative medicine (CAM used alongside with the mainstream medicine) [7]. For the purposes of this review Chinese medicine includes acupuncture, Chinese herbal medicine, remedial massage, exercise and breathing therapy (e.g. Qigong) as well as diet and lifestyle advice in primary health care [8].

We searched major databases, namely AMED, CINAHL, PubMED, Science Direct and Cochrane Library, using specific terms to retrieve surveys published in English. One author (BC) screened all the titles and abstracts to identify relevant studies. Survey studies containing prevalence rates for at least one Chinese medicine modality for treating cancer patients were included. Studies on children were not excluded.

\section{Biomed Central}




\section{Data extraction}

The following data was extracted: country of study, number of study participants, type of study (quantitative, qualitative, mixed), group setting (e.g. hospital, cancer registry), type of cancer, age, gender, ethnicity, marital status, education, prevalence of individual Chinese medicine modality, prevalence, sources of CAM information and reasons for CAM usage.

\section{Quality-assessment}

The quality of the CAM surveys were assessed according to Bishop et al. [9], based on the Strengthening the Reporting of Observational Studies in Epidemiology (STROBE) statement [10]. Reported information was assessed with scores which were weighted for importance. Both authors (BC and CAS) scored the included articles. Final scores were consensus of both authors. Four articles [11-14] were primarily qualitative and therefore not assessed. Three items were scored a maximum of two points, eight items one point and six items 0.5 points. The maximum total score was 17 .

\section{Data analysis}

We described the general characteristics of users of Chinese medicine including both Chinese medicine specific studies and Chinese medicine embedded within CAM studies. Data was analysed with SPSS Statistics 17.0 (IBM, USA). Descriptive statistics, means, medians, ranges, frequencies and percentages characterised the studies.

\section{Results}

The search identified a total of 411 studies for screening. Ninety nine screened articles were retrieved for further evaluation. Eighty one studies met the inclusion criteria and were included in this review (Figure 1).

\section{Characteristics of the studies}

The included 81 studies spanned a period of 15 years (Table 1), with the majority published in the last five years $(60.5 \%)$. While the surveys were carried out around the world, a large number of surveys were conducted in North America, the United States (US) in particular (33.3\%). Sample sizes of the studies ranged from 16 to 22,352 with a median of 189 participants. Two thirds of the participants were female (66.7\%). Participants had a mean age of $56.0 \pm 11.9$ years (mean \pm standard deviation, SD) (ranging from 3 to 71 years), were married or in a de facto marriage (70.6\%) and had completed high school education (35.8\%). The majority (84.5\%) were of Caucasian ethnicity. Survey participants were recruited from hospital settings including outpatient clinics, cancer institutes and palliative care (70.4\%), with convenience sampling $(61 \%)$. Participants had a range of cancers

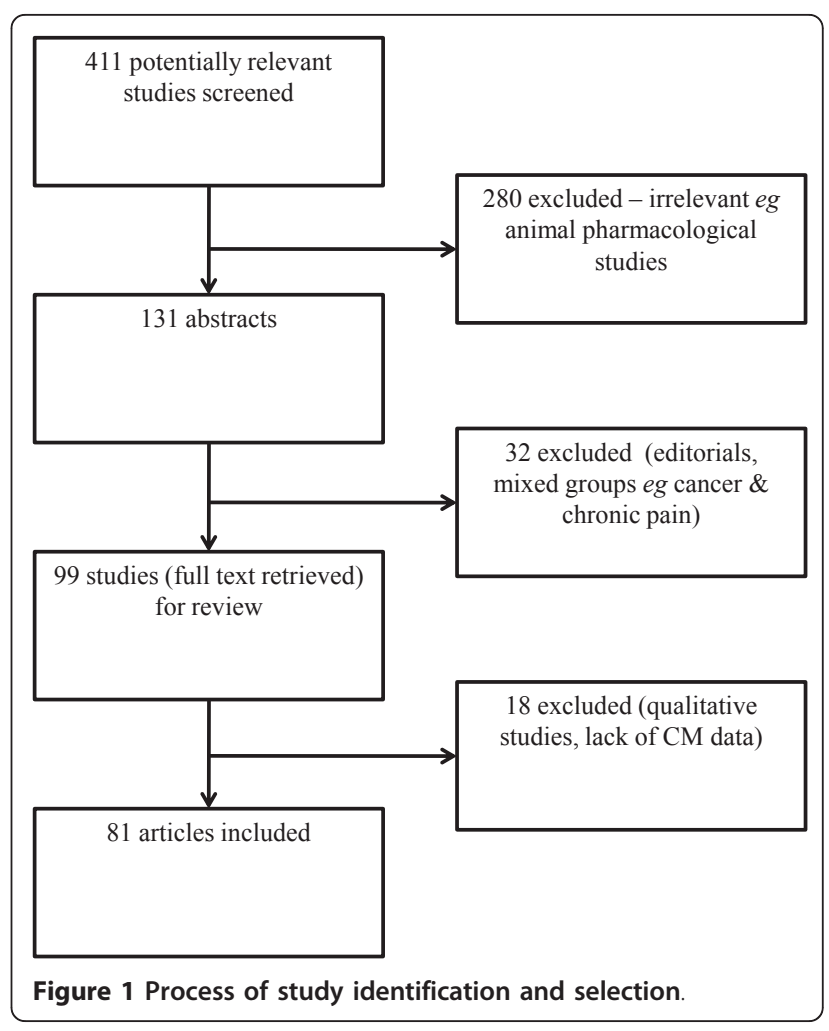

(49.4\%); however, a significant focus was on women with breast cancer (25.9\%). Most studies used a self-administered questionnaire (52\%).

\section{Prevalence of Chinese medicine use}

Seventy four studies reported the rates of CAM usage which ranged from 2.6 to $100 \%$. Acupuncture was the most frequently reported Chinese medicine modality included within CAM. A total of 71 studies reported data on acupuncture. Other less commonly reported modalities included Qigong, Chinese herbal medicine, Taichi, acupressure, moxibustion, Chinese dietary therapy, Chinese massage and cupping.

We examined the prevalence of Chinese medicine usage and reported the range and a mean prevalence (Table 2). Chinese herbal medicine was the most frequently used modality within Chinese medicine; however data were only available from 11 of the 81 studies. Usage ranged from a low prevalence of $0.7 \%$ to a high prevalence of $94.4 \%$, with an average use rate of $35.6 \%$. Acupuncture prevalence ranged from 0.2 to $17.1 \%$ with a mean of $4.5 \%$ extracted from 71 studies. Usage of Qigong by cancer patients was reported in 17 studies with a mean prevalence rate of $12.7 \%$. Usage reported in these studies ranged from 0.4 to $100 \%$. Taichi prevalence ranged from 1.7 to $40.6 \%$ reported in ten studies with a mean of $9.0 \%$. Other Chinese medicine modalities (acupressure, Chinese dietary therapies, Chinese massage, moxibustion and cupping) 
Table 1 Characteristics of included studies $(n=81)$.

\begin{tabular}{|c|c|c|}
\hline & Number of studies & $\%$ \\
\hline \multicolumn{3}{|l|}{ Year (in 5-year blocks) } \\
\hline 2010 & 7 & 8.6 \\
\hline 2009-2005 & 49 & 60.5 \\
\hline $2004-2000$ & 22 & 27.2 \\
\hline 1999-1995 & 3 & 3.7 \\
\hline \multicolumn{3}{|l|}{ Country (by region) } \\
\hline North America & 35 & 43.2 \\
\hline UK \& Europe & 20 & 24.7 \\
\hline Asia & 19 & 23.5 \\
\hline Middle East & 3 & 3.7 \\
\hline Australia and New Zealand & 3 & 3.7 \\
\hline Multiple & 1 & 1.2 \\
\hline \multicolumn{3}{|l|}{ Country or region (by individual countries or regions) } \\
\hline US & 27 & 33.3 \\
\hline Canada & 8 & 9.9 \\
\hline UK & 7 & 8.6 \\
\hline Europe & 6 & 7.4 \\
\hline Taiwan & 4 & 4.9 \\
\hline Other individual countries & 29 & 35.9 \\
\hline \multicolumn{3}{|l|}{ Group setting } \\
\hline Hospital including outpatient clinics, cancer institutes, palliative care & 57 & 70.4 \\
\hline Cancer/tumour registry & 12 & 14.8 \\
\hline General Population & 6 & 7.4 \\
\hline Other & 6 & 7.4 \\
\hline \multicolumn{3}{|l|}{ Data Collection Methods } \\
\hline Self-report questionnaire & 42 & 51.9 \\
\hline Interviewer led (in person or telephone) & 37 & 45.7 \\
\hline Database e.g. insurance claims & 2 & 2.5 \\
\hline \multicolumn{3}{|l|}{ Sampling method } \\
\hline Random & 18 & 22.2 \\
\hline Systematic & 6 & 7.4 \\
\hline Stratified & 7 & 8.6 \\
\hline Convenience & 50 & 61.7 \\
\hline \multicolumn{3}{|l|}{ Cancer type } \\
\hline Various (mixed cancers within groups) & 40 & 49.4 \\
\hline Breast & 21 & 25.9 \\
\hline Prostate & 5 & 6.2 \\
\hline Other & 15 & 18.5 \\
\hline \multicolumn{3}{|l|}{ Gender, mean \% } \\
\hline Female & & 66.7 \\
\hline Male & & 33.2 \\
\hline Age, mean (Missing data $=31$ ) & 56.0 & \\
\hline \multicolumn{3}{|l|}{ Marital status, mean \% (Missing data $=34)$} \\
\hline Married or de-facto & & 70.6 \\
\hline Other & & 29.4 \\
\hline \multicolumn{3}{|l|}{ Education, mean $\%($ Missing data $=27)$} \\
\hline Primary School & & 12.3 \\
\hline High School & & 35.8 \\
\hline University & & 18.5 \\
\hline
\end{tabular}


Table 2 Prevalence of CAM and Chinese Medicine usage

\begin{tabular}{ccccc}
\hline Modality (No. of studies) & Prevalence Mean \% & SD & Prevalence Min \% & Prevalence Max \% \\
\hline CAM (74) & 49.3 & 24.5 & 2.6 & 100 \\
Chinese herbal medicine (11) & 35.6 & 42.1 & 0.7 & 94.4 \\
Mixed Chinese medicine (19) & 17.8 & 28.6 & 0.3 & 100 \\
Chinese dietary therapy (1) & 16.7 & - & 16.7 & 16.7 \\
Qigong (17) & 12.7 & 25.2 & 0.4 & 100 \\
Taichi (10) & 9.0 & 11.5 & 1.7 & 40.6 \\
Acupressure (6) & 6.3 & 6.4 & 1.1 & 18.8 \\
Acupuncture (71) & 4.5 & 3.8 & 0.2 & 17.1 \\
Moxibustion (2) & 2.4 & 1.1 & 1.7 & 3.2 \\
Chinese massage (1) & 2.4 & - & 2.4 & 1.3 \\
Cupping (1) & 1.3 & - & 1.3 & 1.3 \\
\hline
\end{tabular}

were reported with few data in the 11 studies covering these modalities (Table 2). Mixed Chinese medicine prevalence rates (where cancer patients reported using several Chinese modalities concurrently) were also reported. Nineteen of the studies reported such data with a mean prevalence of $17.8 \%$ (ranging from 0.3 to $100 \%$ ).

\section{Use patterns of Chinese medicine modalities}

Our search identified nine studies that provided detailed data on the usage patterns of Chinese medicine [11,15-22]. The aims of these studies were quite diverse. We were not able to provide a systematic summary of these data but a narrative summary.

Studies examining patterns of Chinese medicine usage varied in study design. One study used qualitative methods [11]; another study used a retrospective analysis of insurance registration and claim datasets [20], and seven studies were questionnaire-based surveys [15-19,21,22]. All seven surveys included Chinese or other Asian populations (Mainland China, Taiwan, Hong Kong, Singapore), or Chinese immigrants in Canada. Seven studies reported an overall Chinese medicine usage rate attributed to Chinese medicinal herbs, Qigong, acupuncture and moxibustion.

Within the nine studies, usage of Chinese medicinal herbs varied widely; however the majority reported high usage of $94.4 \%$ [19], 93.75\% [11], 86.4\% [17], 76.75\% [15] and one low rate of $2.48 \%$ [20]. Examples are presented in the following studies. Shih et al. [22] reported additional details on the types of Chinese medicinal herbs and related modalities in particular food supplements. Forty five percent of participants used bird (swallow) nests and 28.6\% chicken essence; $53 \%$ used prescribed herbs, of which $15.4 \%$ used Lingzhi, and $8 \%$ used Chinese herbal formulae. In the study by $\mathrm{Xu}$ et al. [11], 50\% of participants used individually tailored herbs, $6 \%$ standard herbal formulae and 38\% both types. $\mathrm{Xu}$ et al. reported that all participants $(n=16)$ practiced Qigong.

\section{Characteristics of Chinese medicine users}

Three $[17,18,21]$ of the nine studies reported the characteristics of Chinese medicine users. Pu et al. [21] surveyed 2034 patients with cervical, breast, lung, liver and colorectal cancers and highlighted patients' usage of Chinese medicine modalities according to cancer types. Chinese medicine as a broad modality was more likely to be used by patients with breast, lung, liver and colorectal cancers whereas acupuncture was more likely to be used by liver and colorectal patients. $\mathrm{Pu}$ et al. examined the correlation of socio-economic factors (e.g. religion, education and income) with Chinese medicine usage. While more Buddhists used Chinese medicine, acupuncture usage was not distinctive in patients with any religion. Acupuncture users were mostly female cancer patients with higher education. According to the study by $\mathrm{Pu}$ et $a l$., participants earning a higher income were about $52 \%$ more likely than lower income groups to use Chinese medicine. Similarly, Cui et al. [17] found that more participants with a higher education and higher income used Chinese herbal medicine. Ferro et al. [18] found that Chinese medicine was used by less acculturated patients twice as much as acculturated patients.

\section{Motivation to use and the perceived effectiveness of Chinese medicine}

Motivation to use and the perceived effectiveness of Chinese medicine modalities were reported in three studies [11,15,17]. Xu et al. [11] highlighted four important reasons for Chinese medicine usage among 28 Chinese cancer patients: (1) Chinese medicine as a popular and culturally acceptable process of self-help, (2) fear of chemotherapy damaging the vital essence, (3) importance of individualised prescriptions and (4) empowerment with self-help. Almost all participants used Chinese medicine to avoid or reduce adverse effects from cancer treatment. Overall, health benefits, quality of life and ability to function were significantly improved with Chinese medicine. Benefits attributed to Chinese medicine 
included reduced fatigue, nausea and vomiting, constipation, stress, weakness and weight gain.

Cui et al. [17] found that the most common reason for using Chinese herbal medicine among breast cancer patients was cancer treatment $(81.5 \%)$, followed by immune system enhancement (12\%), metastasis prevention or side effect management (7.9\%), and the reduction of menopausal symptoms (4.7\%). Chinese herbal medicine was perceived to be effective or very effective for cancer treatment (78.7\%), and 77\% of female patients perceived Chinese medicine to be very effective or effective for immune system enhancement. Similar levels of effectiveness were reported for metastasis management and the reduction of menopausal symptoms. Acupuncture, on the other hand, was reported to be less effective with only $48.1 \%$ of users considering it to be effective. Chen et al. [15] found far more sceptical views among breast cancer patients with only $52 \%$ of patients perceiving Chinese herbal medicine as effective and $4 \%$ as very effective in assisting cancer treatment.

\section{Study quality}

Overal study quality (Additional file 1) was scored between 32 and $94 \%$, with $95 \%$ of studies scoring above a $50 \%$ threshold for the 77 quantitiave studies [15-91]. Fourty four studies omitted piloting of instruments. Fourty seven studies used convenience sampling. Only eight studies reported non-response bias. Overall measures of socioeconomic status were included and reported. All studies reported prevalence but many failed to examine the reasons for usage. Many cancer studies $(n=11)$ reported the usage starting from the time of diagnosis, thereby omitting patterns of usage prior to diagnosis.

\section{Discussion}

Acupuncture was the most frequently reported Chinese medicine modality with nearly $90 \%$ of the studies containing prevalence data. However, among more comprehensive studies of Chinese medicine modalities, Chinese herbal medicine was the most commonly used form of Chinese medicine.

Increasing prevalence of CAM usage by cancer patients reflects the growing use of CAM over time [92]. Our review suggests a higher CAM prevalence compared with a prevalence of $31.4 \%$, and a range of 7-64\%, reported by Ernst [93]. However, unlike Ernst, we were unable to access non-English language publications.

Major limitations of the studies on the use of Chinese medicine in relation to cancer are as follows. Firstly, nonEnglish language studies, in particular those written in Chinese, were not reviewed and should be included in future studies. Moreover, the inability to access the EMBASE database might have excluded some English language reports. Secondly, the variation in the wide range of CAM use is likely explainable by different cultural contexts, understandings and definitions of what constitutes CAM. Thirdly, incomplete reporting of the definition of CAM adopted by many studies, and the lack of rationale for selecting Chinese medicine modalities were not uncommon. Furthermore, extensive demographic characteristics and related details were not reported. Sampling of the participant population and the generalisability of the findings was not justified. Fourthly, qualitative research accompanied by cross sectional and longitudinal surveys and additional information about cultural and ethnic populations was insufficient for cross cultural comparisons. Further studies should address these limitations.

\section{Conclusion}

Our results show that Chinese medicine, in particular Chinese herbal medicine, is commonly used by cancer patients. Further research is warranted to include studies not written in English.

\section{Additional material}

Additional file 1: Summary of QAT Scores $(n=77)$. Summary of QAT Scores

\section{Abbreviations}

CAM: complementary and alternative medicine; STROBE: Strengthening the Reporting of Observational Studies in Epidemiology; US: United States; SD: standard deviation

\section{Acknowledgements}

The authors wish to thank Carole Do for her preliminary database searches and research which laid the groundwork for this study. This study was funded by the Centre for Complementary Medicine Research, University of Western Sydney, Australia.

\section{Authors' contributions}

BC searched the databases, performed statistical analysis and drafted the manuscript. CAS conceived the study and drafted the manuscript. Both authors read and approved the final version of the manuscript.

\section{Competing interests}

The authors declare that they have no competing interests.

Received: 14 December 2010 Accepted: 9 June 2011

Published: 9 June 2011

\section{References}

1. Amin A, Kucuk O, Khuri FR, Shin DM: Perspectives for cancer prevention with natural compounds. J Clinical Oncol 2009, 27:2712.

2. Liu LJ, Guo CJ, Jiao XM: Effect of acupuncture on immunologic function and histopathology of transplanted mammary cancer in mice. Zhongguo Zhong Xi Yi Jie He Za Zhi 1995, 15(10):615-7.

3. Wu B, Zhou R, Zhou M: Effect of acupuncture on interleukin-2 level and NK cell immunoactivity of peripheral blood of malignant tumor patients. Zhongguo Zhong Xi Yi Jie He Za Zhi 1994, 14:537-9.

4. Dundee J, Ghaly R, Fitzpatrick K, Abram W, Lynch G: Acupuncture prophylaxis of cancer chemotherapy-induced sickness. J R Soc Med 1989, 82:268-71. 
5. Shen J, Wenger N, Glaspy J, Hays R, Albert P, Choi C, Shekelle P. Electroacupuncture for control of myeloablative chemotherapy-induced emesis: a randomized controlled trial. JAMA 2000, 284:2755-61.

6. Aglietti L, Roila F, Tonato M, Basurto C, Bracarda S, Picciafuoco M, Ballatori E, Del Favero A: A pilot study of metoclopramide, dexamethasone, diphenhydramine and acupuncture in women treated with cisplatin. Cancer Chemother Pharmacol 1990, 26:239-240.

7. About Complementary Medicine: Definition of complementary medicine. [http://www.nicm.edu.au/content/view/31/35/.

8. Health Services: Acupuncture. [http://www.acupuncture.org.au/ acupuncture.cfm].

9. Bishop FL, Prescott P, Chan YK, Saville J, von Elm E, Lewith GT: Prevalence of complementary medicine use in pediatric cancer: a systematic review. Pediatrics 2010, 125:768-776.

10. Von Elm E, Altman DG, Egger M, Pocock SJ, Gøtzsche PC, Vandenbroucke JP: The Strengthening the Reporting of Observational Studies in Epidemiology (STROBE) statement: guidelines for reporting observational studies. Bull World Health Organ 2007, 85:867-872.

11. Xu W, Towers A, Li P, Collet J: Traditional Chinese medicine in cancer care: perspectives and experiences of patients and professionals in China. Eur J Cancer Care (Engl) 2006, 15:397-403.

12. Canales MK, Geller BM: Surviving breast cancer: the role of complementary therapies. Fam Community Health 2003, 26:11-24.

13. Hök J, Tishelman C, Ploner A, Forss A, Falkenberg T: Mapping patterns of complementary and alternative medicine use in cancer: An explorative cross-sectional study of individuals with reported positive" exceptional" experiences. BMC Complement Altern Med 2008, 8:48.

14. Singh $H$, Maskarinec $G$, Shumay DM: Understanding the motivation for conventional and complementary/alternative medicine use among men with prostate cancer. Integr Cancer Ther 2005, 4:187-194.

15. Chen Z, Gu K, Zheng Y, Zheng W, Lu W, Shu XO: The use of complementary and alternative medicine among Chinese women with breast cancer. J Altern Complement Med 2008, 14:1049-1055.

16. Chow WH, Chang P, Lee SC, Wong A, Shen HM, Verkooijen HM: Complementary and alternative medicine among Singapore cancer patients. Ann Acad Med Singapore 2010, 39:129-135.

17. Cui Y, Shu XO, Gao Y, Wen W, Ruan ZX, Jin F, Zheng W: Use of complementary and alternative medicine by Chinese women with breast cancer. Breast Cancer Res Treat 2004, 85:263-270.

18. Ferro M, Leis A, Doll R, Chiu L, Chung M, Barroetavena M: The impact of acculturation on the use of traditional Chinese medicine in newly diagnosed Chinese cancer patients. Support Care Cancer 2007, 15:985-992.

19. Lam YC, Cheng CW, Peng H, Law CK, Huang X, Bian Z: Cancer patients' attitudes towards Chinese medicine: a Hong Kong survey. Chin Med 2009, 4:25

20. Lin Y, Chen K, Chiu J: Prevalence, patterns, and costs of Chinese medicine use among prostate cancer patients: A population-based study in Taiwan. Integr Cancer Ther 2010, 9:16-23.

21. Pu C, Lan V, Lan C, Lang H: The determinants of traditional Chinese medicine and acupuncture utilization for cancer patients with simultaneous conventional treatment. Eur J Cancer Care (Engl) 2008, 17:340-349.

22. Shih V, Chiang J, Chan A: Complementary and alternative medicine (CAM) usage in Singaporean adult cancer patients. Ann Oncol 2009 20:752-7.

23. Can G, Erol O, Aydiner A, Topuz E: Quality of life and complementary and alternative medicine use among cancer patients in Turkey. Eur J Oncol Nurs 2009, 13:287-94.

24. Hamidah A, Rustam ZA, Tamil AM, Zarina LA, Zulkifli ZS, Jamal R: Prevalence and parental perceptions of complementary and alternative medicine use by children with cancer in a multi ethnic Southeast Asian population. Pediatr Blood Cancer 2009, 52:70-74.

25. Johannessen $\mathrm{H}$, von Bornemann Hielmborg J Pasquarelli E, Fiorentini $\mathrm{G}, \mathrm{D}$ Costanzos F, Miccinesi G: Prevalence in the use of complementary medicine among cancer patients in Tuscany, Italy. Tumori 2008, 94:406-10.

26. McKay DJ, Bentley JR, Grimshaw RN: Complementary and alternative medicine in gynaecologic oncology. J Obstet Gynaecol Can 2005, 27:562-568.

27. Molassiotis A, Browall M, Milovics L, Panteli V, Patiraki E, Fernandez OP: Complementary and alternative medicine use in patients with gynecological cancers in Europe. Int I Gynecol Cancer 2006, 16(Suppl 1):219-224

28. Shakeel M, Newton J, Bruce J, Ah-See K: Use of complementary and alternative medicine by patients attending a head and neck oncology clinic. J Laryngol Otol 2008, 122:1360-1364

29. Wilkinson S, Farrelly S, Low J, Chakraborty A, Williams R: The use of complementary therapy by men with prostate cancer in the UK. Eur J Cancer Care (Engl) 2008, 17:492-499.

30. Yang C, Chien LY, Tai CJ: Use of complementary and alternative medicine among patients with cancer receiving outpatient chemotherapy in Taiwan. J Altern Complement Med 2008, 14:413-416.

31. Akyuz A, Dede M, Cetinturk A, Yavan T, Yenen MC, Sarici SU, Dilek S: Selfapplication of complementary and alternative medicine by patients with gynecologic cancer. Gynecol Obstet Invest 2007, 64:75-81.

32. Goldstein MS, Lee JH, Ballard Barbash R, Brown ER: The use and perceived benefit of complementary and alternative medicine among Californians with cancer. Psychooncology 2008, 17:19-25.

33. Helyer LK, Chin S, Chui BK, Fitzgerald B, Verma S, Rakovitch E, Dranitsaris G, Clemons M: The use of complementary and alternative medicines among patients with locally advanced breast cancer - a descriptive study. BMC cancer 2006, 6:39.

34. Lawsin C, DuHamel K, Itzkowitz SH, Brown K, Lim H, Thelemaque L, Jandorf L: Demographic, medical, and psychosocial correlates to CAM use among survivors of colorectal cancer. Support Care Cancer 2007, 15:557-564.

35. Mao JJ, Farrar JT, Xie SX, Bowman MA, Armstrong K: Use of complementary and alternative medicine and prayer among a national sample of cancer survivors compared to other populations without cancer. Complement Ther Med 2007, 15:21-29.

36. Mertens AC, Sencer S, Myers CD, Recklitis C, Kadan Lottick N, Whitton J, Marina N, Robison LL, Zeltzer L: Complementary and alternative therapy use in adult survivors of childhood cancer: A report from the Childhood Cancer Survivor Study. Pediatr Blood Cancer 2008, 50:90-97.

37. Molassiotis A, Scott JA, Kearney N, Pud D, Magri M, Selvekerova S, Bruyns I, Fernadez-Ortega P, Panteli V, Margulies A: Complementary and alternative medicine use in breast cancer patients in Europe. Support Care Cancer 2006, 14:260-267.

38. Montazeri A, Sajadian A, Ebrahimi M, Haghighat S, Harirchi I: Factors predicting the use of complementary and alternative therapies among cancer patients in Iran. Eur J Cancer Care (Engl) 2007, 16:144-149.

39. Mueller CM, Mai PL, Bucher J, Peters JA, Loud JT, Greene MH: Complementary and alternative medicine use among women at increased genetic risk of breast and ovarian cancer. BMC Complement Altern Med 2008, 8:17.

40. Wells M, Sarna L, Cooley ME, Brown JK, Chernecky C, Williams RD, Padilla G, Danao LL: Use of complementary and alternative medicine therapies to control symptoms in women living with lung cancer. Cancer Nurs 2007, 30:45-55.

41. Fox S, Laws ER Jr, Anderson F Jr, Farace E: Complementary therapy use and quality of life in persons with high-grade gliomas. J Neurosci Nurs 2006, 38:212-220.

42. Gray RE, Fitch M, Goel V, Franssen E, Labrecque M: Utilization of complementary/alternative services by women with breast cancer. $J$ Health Soc Policy 2003, 16:75-84

43. Habermann TM, Thompson CA, LaPlant BR, Bauer BA, Janney CA, Clark MM Rummans TA, Maurer MJ, Sloan JA, Geyer SM: Complementary and alternative medicine use among long term lymphoma survivors: A pilot study. Am J Hematol 2009, 84:795-798.

44. Harris P, Finlay IG, Cook A, Thomas K, Hood K: Complementary and alternative medicine use by patients with cancer in Wales: a cross sectional survey* 1 . Complement Ther Med 2003, 11:249-253.

45. Hyodo I, Amano N, Eguchi K, Narabayashi M, Imanishi J, Hirai M, Nakano T, Takashima S: Nationwide survey on complementary and alternative medicine in cancer patients in Japan. J Clin Oncol 2005, 23:2645-2654.

46. Kim MJ, Kim DR, Sohn WS, Kim J, Han CJ, Nam HS, Kim CH: Use of complementary and alternative medicine among Korean cancer patients. Korean J Intern Med 2004, 19:250-256.

47. Lewith G, Broomfield J, Prescott P: Complementary cancer care in Southampton: a survey of staff and patients. Complement Ther Med 2002, 10:100-106.

48. Molassiotis A, Fernadez-Ortega P, Pud D, Ozden G, Scott JA, Panteli V, Margulies A, Browall M, Magri M, Selvekerova S: Use of complementary 
and alternative medicine in cancer patients: a European survey. Ann Oncol 2005, 16:655-663.

49. Molassiotis A, Fernandez-Ortega P, Pud D, Ozden G, Platin N, Hummerston S, Scott JA, Panteli V, Gudmundsdottir G, Selvekerova S: Complementary and alternative medicine use in colorectal cancer patients in seven European countries. Complement Ther Med 2005, 13:251-257.

50. Molassiotis A, Margulies A, Fernandez-Ortega P, Pud D, Panteli V, Bruyns I, Scott JA, Gudmundsdottir G, Browall M, Madsen E: Complementary and alternative medicine use in patients with haematological malignancies in Europe. Complement Ther Clin Pract 2005, 11:105-110.

51. Molassiotis A, Ozden G, Platin N, Scott JA, Pud D, Fernandez OP, Milovics L, Panteli V, Gudmundsdottir G, Browall M: Complementary and alternative medicine use in patients with head and neck cancers in Europe. Eur J Cancer Care (Engl) 2006, 15:19-24.

52. Molassiotis A, Panteli V, Patiraki E, Ozden G, Platin N, Madsen E, Browall M, Fernandez-Ortega P, Pud D, Margulies A: Complementary and alternative medicine use in lung cancer patients in eight European countries. Complement Ther Clin Pract 2006, 12:34-39.

53. Schieman C, Rudmik LR, Dixon E, Sutherland F, Bathe OF: Complementary and alternative medicine use among general surgery, hepatobiliary surgery and surgical oncology patients. Can J Surg 2009, 52:422-426.

54. Scott JA, Kearney N, Hummerston S, Molassiotis A: Use of complementary and alternative medicine in patients with cancer: a UK survey. Eur J Oncol Nurs 2005, 9:131-137.

55. Talmi YP, Yakirevitch A, Migirov L, Horowitz Z, Bedrin L, Simon Z, Pfeffer MR: Limited use of complementary and alternative medicine in Israeli head and neck cancer patients. Laryngoscope 2005, 115:1505-1508.

56. Tam K, Cheng DKL, Ng T, Ngan HYS: The behaviors of seeking a second opinion from other health-care professionals and the utilization of complementary and alternative medicine in gynecologic cancer patients. Support Care Cancer 2005, 13:679-684.

57. van der Weg F, Streuli RA: Use of alternative medicine by patients with cancer in a rural area of Switzerland. Swiss Med Wkly 2003, 133:233-240.

58. Yap KPL, McCready DR, Fyles A, Manchul L, Trudeau M, Narod S: Use of alternative therapy in postmenopausal breast cancer patients treated with tamoxifen after surgery. Breast J 2004, 10:481-486.

59. Yates JS, Mustian KM, Morrow GR, Gillies LJ, Padmanaban D, Atkins JN, Issell B, Kirshner JJ, Colman LK: Prevalence of complementary and alternative medicine use in cancer patients during treatment. Support Care Cancer 2005, 13:806-811.

60. Ashikaga T, Bosompra K, O'Brien P, Nelson L: Use of complimentary and alternative medicine by breast cancer patients: prevalence, patterns and communication with physicians. Support Care Cancer 2002, 10:542-548.

61. Begbie SD, Kerestes ZL, Bell DR: Patterns of alternative medicine use by cancer patients. Med J Aust 1996, 165:545-547.

62. Boon HS, Olatunde F, Zick SM: Trends in complementary/alternative medicine use by breast cancer survivors: comparing survey data from 1998 and 2005. BMC Womens Health 2007, 7:4.

63. Burstein HJ, Gelber S, Guadagnoli E, Weeks JC: Use of alternative medicine by women with early-stage breast cancer. N Engl J Med 1999, 340:1733-1739.

64. Chrystal K, Allan S, Forgeson G, Isaacs R: The use of complementary/ alternative medicine by cancer patients in a New Zealand regional cancer treatment centre. N Z Med J 2003, 116:1168.

65. Corner J, Yardley J, Maher E, Roffe L, Young T, Maslin-Prothero S, Gwilliam C, Haviland J, Lewith G: Patterns of complementary and alternative medicine use among patients undergoing cancer treatment. Eur J Cancer Care (Engl) 2009, 18:271-279.

66. DiGianni LM, Kim HT, Emmons K, Gelman R, Kalkbrenner KJ, Garber JE: Complementary medicine use among women enrolled in a genetic testing program. Cancer Epidemiol Biomarkers Prev 2003, 12:321-326.

67. Hann D, Baker F, Denniston M, Entrekin N: Long-term breast cancer survivors' use of complementary therapies: perceived impact on recovery and prevention of recurrence. Integr Cancer Ther 2005, 4:14-20.

68. Hann D, Baker F, Roberts C, Witt C, McDonald J, Livingston M, Ruiterman J, Ampela R, Crammer C, Kaw O: Use of complementary therapies among breast and prostate cancer patients during treatment: a multisite study. Integr Cancer Ther 2005, 4:294-300.
69. Henderson J, Donatelle R: Complementary and alternative medicine use by women after completion of allopathic treatment for breast cancer. Altern Ther Health Med 2004, 10:52-57.

70. Heusser P, Braun S, Ziegler R, Bertschy M, Helwig S, van Wegberg B, Cerny T: Palliative in-patientcancer treatment in an anthroposophic hospital: I. Treatment patterns and compliance with anthroposophic Medicine*. Forsch Komplementmed 2006, 13:94-100.

71. Kremser T, Evans A, Moore A, Luxford K, Begbie S, Bensoussan A, Marigliani $\mathrm{R}$, Zorbas $\mathrm{H}$ : Use of complementary therapies by Australian women with breast cancer. Breast 2008, 17:387-394.

72. Lafferty WE, Bellas A, Corage Baden A, Tyree PT, Standish LJ, Patterson R: The use of complementary and alternative medical providers by insured cancer patients in Washington state. Cancer 2004, 100:1522-1530.

73. Lee MM, Chang JS, Jacobs B, Wrensch MR: Complementary and alternative medicine use among men with prostate cancer in 4 ethnic populations. Am J Public Health 2002, 92:1606-1609.

74. Lengacher CA, Bennett MP, Kip KE, Keller R, LaVance MS, Smith LS, Cox CE: Frequency of use of complementary and alternative medicine in women with breast cancer. Oncol Nurs Forum 2002, 29:1445-1452.

75. Li-chun C: Patterns of complementary therapy use by homebound cancer patients in Taiwan. Appl Nurs Res 2004, 17:41-47.

76. Oneschuk D, Hanson J, Bruera E: Complementary therapy use: a survey of community-and hospital-based patients with advanced cancer. Palliat Med 2000, 14:432-434.

77. Pud D, Kaner E, Morag A, Ben-Ami S, Yaffe A: Use of complementary and alternative medicine among cancer patients in Israel. Eur J Oncol Nurs 2005, 9:124-130.

78. Rees R, Feigel I, Vickers A, Zollman C, McGurk R, Smith C: Prevalence of complementary therapy use by women with breast cancer: $a$ population-based survey. Eur J Cancer 2000, 36:1359-1364.

79. Shen J, Andersen R, Albert PS, Wenger N, Glaspy J, Cole M, Shekelle P: Use of complementary/alternative therapies by women with advanced-stage breast cancer. BMC Complement Altern Med 2002, 2:8.

80. Shumay DM, Maskarinec G, Gotay CC, Heiby EM, Kakai H: Determinants of the degree of complementary and alternative medicine use among patients with cancer. J Altern Complement Med 2002, 8:661-671.

81. Sparber A, Bauer L, Curt G, Eisenberg D, Levin T, Parks S, Steinberg S, Wootton J: Use of complementary medicine by adult patients participating in cancer clinical trials. Oncol Nurs Forum 2000, 27:623-630.

82. Tovey P, Broom A, Chatwin J, Ahmad S, Hafeez M: Use of traditional, complementary and allopathic medicines in Pakistan by cancer patients. Rural Remote Health 2005, 5:447.

83. VandeCreek $L$, Rogers $E$, Lester J: Use of alternative therapies among breast cancer outpatients compared with the general population. Altern Ther Health Med 1999, 5:71-76.

84. Vapiwala N, Mick R, Hampshire MK, Metz JM, DeNittis AS: Patient initiation of complementary and alternative medical therapies (CAM) following cancer diagnosis. Cancer J 2006, 12:467-474.

85. Yoshimura K, Ichioka K, Terada N, Terai A, Arai Y: Use of complementary and alternative medicine by patients with localized prostate carcinoma: study at a single institute in Japan. Int J Clin Oncol 2003, 8:26-30.

86. Broom A, Wijewardena K, Sibbritt D, Adams J, Nayar K: The use of traditional, complementary and alternative medicine in Sri Lankan cancer care: Results from a survey of 500 cancer patients. Public Health 2010, 124:232-237

87. Lim C, Ng A, Loh $\mathrm{K}$ : Use of complementary and alternative medicine in head and neck cancer patients. J Laryngol Otol 2010, 124:529-532.

88. Pedersen CG, Christensen S, Jensen AB, Zachariae R: Prevalence, sociodemographic and clinical predictors of post-diagnostic utilisation of different types of complementary and alternative medicine (CAM) in a nationwide cohort of Danish women treated for primary breast cancer. Eur J Cancer 2009, 45:3172-3181.

89. Supoken A, Chaisrisawatsuk T, Chumworathayi B: Proportion of gynecologic cancer patients using complementary and alternative medicine. Asian Pac J Cancer Prev 2009, 10:779-782.

90. Fouladbakhsh JM, Stommel M: Gender, symptom experience, and use of complementary and alternative medicine practices among cancer survivors in the US cancer population. Oncol Nurs Forum 2010, 37:7-15. 
91. Wyatt G, Sikorskii A, Wills CE, Su H: Complementary and alternative medicine use, spending, and quality of life in early stage breast cancer. Nurs Res 2010, 59:58-66.

92. Adams J: Researching Complementary and Alternative Medicine Abingdon: Routledge; 2007.

93. Ernst $\mathrm{E}:$ The prevalence of complementary/alternative medicine in cancer. Cancer 1998, 83:777-782.

doi:10.1186/1749-8546-6-22

Cite this article as: Carmady and Smith: Use of Chinese medicine by cancer patients: a review of surveys. Chinese Medicine 2011 6:22.

Submit your next manuscript to BioMed Central and take full advantage of:

- Convenient online submission

- Thorough peer review

- No space constraints or color figure charges

- Immediate publication on acceptance

- Inclusion in PubMed, CAS, Scopus and Google Scholar

- Research which is freely available for redistribution

Submit your manuscript at www.biomedcentral.com/submit 